\title{
Molten Salt as a Green Reaction Medium: Synthesis of Polyureas Containing 4-phenylurazole Moiety in the Main Chain in the Presence of Tetrabutylammonium bromide as an Ionic Liquid
}

\author{
Shadpour Mallakpour, Mohammad Dinari
}

Organic Polymer Chemistry Research Laboratory, College of Chemistry, Isfahan University of Technology, Isfahan, 84156-83111, I.R. Iran. E- mail: mallak@cc.iut. ac.ir

(Received: 5 January, 2007; published: 8 April, 2007)

\begin{abstract}
Ionic Liquids (IL)s have been generating increased interest over the last decade. ILs were initially introduced as an alternative green reaction media because of their unique chemical and physical properties of nonvolatility, nonflammability, thermal stability, and controlled miscibility. The step-growth polymerization reactions of 4-phenylurazole (PHU) with various diisocyanates such as hexamethylene diisocyanate ( $\mathrm{HMDI})$, isophorone diisocyanate (IPDI), and toluylene-2,4-diisocyanate (TDI) were performed in the presence of tetrabutylammonium bromide (TBAB) as a reaction medium with or without dibutyltin dilurate (DBTDL) as a catalyst. The polymerization reaction gave similar results in the presence or absence of DBTDL, indicating that, the catalyst is not needed in this process. The resulting polyureas showed high yields and moderate inherent viscosities in a range of $0.23-0.29 \mathrm{dL} / \mathrm{g}$ in $\mathrm{N}, \mathrm{N}$-dimethylformamide (DMF) at $25^{\circ} \mathrm{C}$ and they are soluble in most polar aprotic organic solvents. This method was compared with the polymerization reaction in conventional solvent such as, $\mathrm{N}, \mathrm{N}$-dimethylacetamide (DMAC). In the case of using TBAB, higher yields and inherent viscosities were obtained. All of the above polymers were characterized by FT-IR and thermogravimetric analysis (TGA).
\end{abstract}

Keywords: 4-phenyl urazole; polyureas; inherent viscosity; step-growth polymerization; ionic liquid; tetrabutylammonium bromide

\section{Introduction}

In a search for more efficient and environmentally friendly processes, chemists have recently turned their attention to the new class of potential solvents namely ionic liquids (IL)s in the context of green synthesis [1-3]. ILs have been applied in both academia and industry due to their potential as replacements for volatile organic compounds (VOC)s [4]. Generally, the term of ILs stands for liquids composed of ions. These are usually molten salts or molten oxides. It has been noted that the properties of molten salts as solvents for chemical processes differ from those of aqueous and organic solvents and they are either organic salts or mixtures of salts that are fluid at room or near-room temperature [5]. It is important that ILs are the chemicals that can be applied as both solvents and catalysts in green chemistry processes [6]. Other important properties including large liquids range, high thermal stability, stable in air $[7,8]$ and ability to solvate compounds of widely varying polarity. Most of the ILs can be maintained for a long period of time without any decomposition [9]. These solvents have been used in many chemical transformations 
such as organic, inorganic and polymer synthesis [4, 10-13].

Recently, molten tetrabutylammonium bromide (TBAB) was used as a low toxic and cost-effective IL in a number of useful synthetic transformations [14-19]. This environmental aspects is partly lost when they are used as solvents for polymerization processes in order to isolate the polymer, so it may be necessary to use an organic solvent [20].

Urazole derivatives are very interesting five-membered heterocyclic compounds which contain three nitrogen atoms and two carbonyl groups. They are prepared in five steps from corresponding carboxylic acids and in two steps from corresponding isocyanates. Since, the 4-position of the urazole group can readily be substituted with a wide variety of the functional groups, either aliphatic or aromatic substitution; one can achieve important properties such as supramolecular aggregation by hydrogen bonding, optical activity and liquid crystallinity [21, 22]. Industrially urazole is used in the manufacture of automobile air bags, as a blowing agent in plastics, in the production of herbicides, [23] antifungal compounds and in polymeric materials. It is also used in the manufacture of anti-tumor drugs [24] and as a stabilizer in milk. Urazole is used as a laboratory reagent for synthesizing novel heterocyclic [25] and organometallic compounds. Some urazole derivatives were found to be potent cytotoxic agents in murrain and human cancer cell lines and also reduce DNA synthesis significantly with moderate reduction in RNA synthesis [26, 27].

Polyureas are polyamides of carbonic acid that are tough, high melting, and suitable for fibre applications $[28,29]$. The presence of $-\mathrm{NH}-\mathrm{CO}-\mathrm{NH}$ - functional group in polyureas leads to the $\mathrm{H}$-bonding formation from different sides. Polyureas are very tough materials with high hardness and good chemical resistance. They can be tailor-made to obtain properties which lead to versatile applications such as coating systems for waterproofing and corrosion protection [30]. A number of methods have been used to prepare polyureas, but the best one is the reaction of diamines with diisocyanates. This reaction is a step-growth addition reaction of amine across the carbon-nitrogen double bond and there is no by-product. Polyureas have been used for many applications including encapsulation of pharmaceutical, ink, dyes, and the modification of wool fibres by interfacial grafting techniques [31]. In previous work we reported the polymerization reaction of $\mathrm{PHU}$ with different diisocyanates in conventional organic solvent in the presence of different catalysts such as pyridine and triethylamine [32]. In this work we wish to report the polycondensation of PHU with different readily available diisocyanates in molten TBAB as a reaction medium in the presence and absence of dibutyltin dilurate (DBTDL) as a catalyst and compare it with conventional solution polymerization.

\section{Results and Discussion}

\section{Polymer Synthesis}

As an extension of our studies on the application of green chemistry principles in polymerization reactions, we wish to report a simple, safe and efficient method for reaction of $\mathrm{PHU}$ with readily accessible diisocyanates such as hexamethylene diisocyanate (HMDI) 1, isophorone diisocyanate (IPDI) 2, and toluylene-2,4diisocyanate (TDI) 3 in molten TBAB as homogenizer. The polyureas based on PHU were synthesized by one step high temperature method (Scheme 1). The polymerization reaction was carried out in molten TBAB in the presence and absence of DBTDL as a catalyst. 


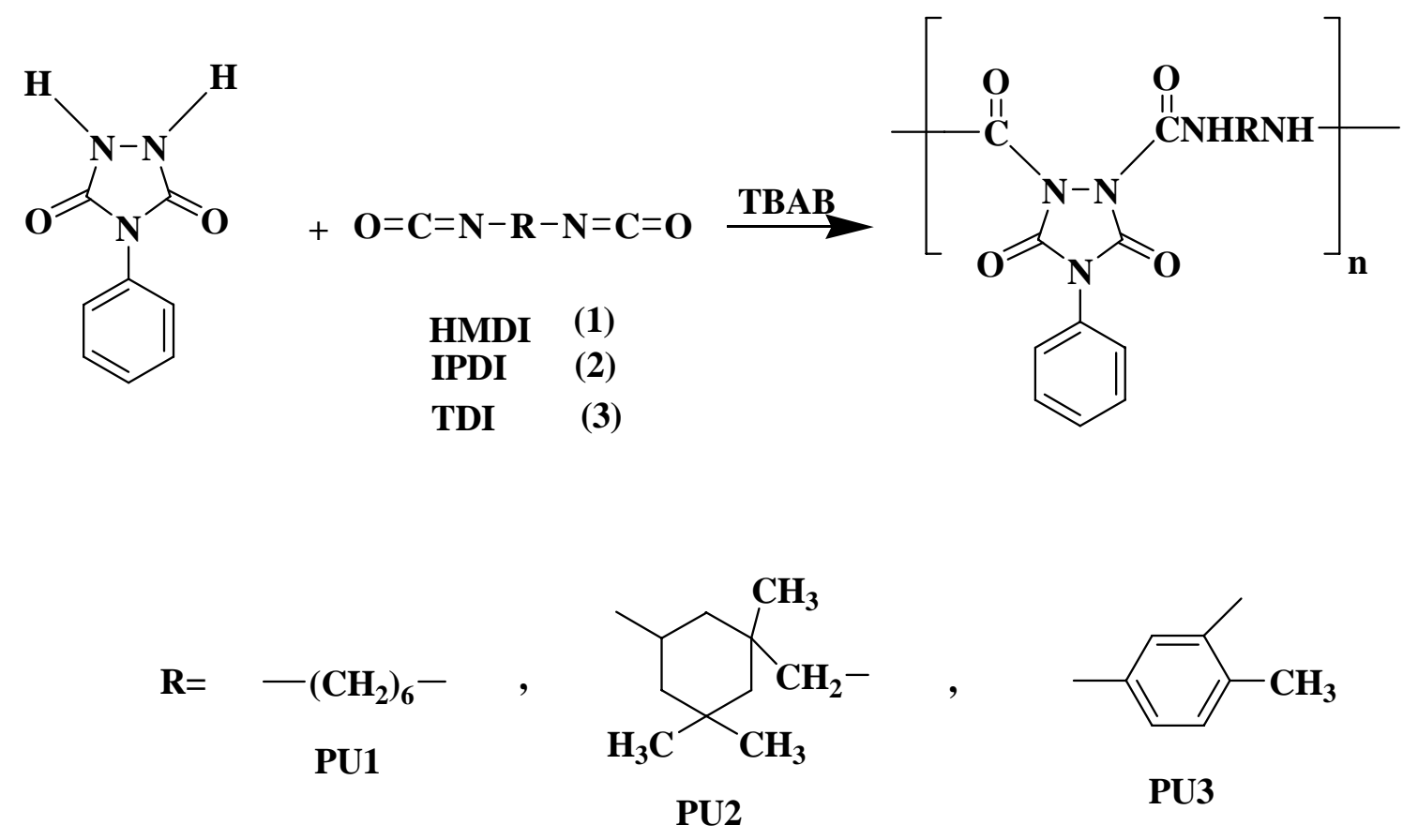

Scheme 1. Polycondensation reactions of PHU with various diisocyanates such as HMDI (1), IPDI (2), TDI (3).

The comparison of these results indicate that DBTDL was not required in this polycondensation, because the inherent viscosities and the yields of polymers did not differ so much, and as a matter of fact, by eliminating DBTDL both cost and pollution will come down. Hence, molten TBAB may act both as a solvent and catalyst in this process. It has been suggested that ILs can produce ordering and also stabilizing the reaction intermediate, thus increasing selectivity and rate of the reaction [33]. The resulting polyureas were obtained in high yields, moderate inherent viscosities and thermal stability. The results are shown in Tables 1 and 2.

Tab. 1. Reaction Conditions for the Polymerization of PHU with Diisocyanates Using TBAB as a Solvent.

\begin{tabular}{|c|c|c|c|c|c|}
\hline Polymer & iisocyanate & Cat. & $\begin{array}{l}\text { Yield } \\
(\%)\end{array}$ & $\begin{array}{l}\text { Inherent } \\
\text { viscosity } \\
(\mathrm{dL} / \mathrm{g})^{\mathrm{a}}\end{array}$ & Color \\
\hline PU1Al & HMDI & - & 92 & 0.29 & $w^{b}$ \\
\hline PU1BI & HMDI & DBTDL & 89 & 0.27 & W \\
\hline PU2AI & IPDI & - & 82 & 0.23 & W \\
\hline PU2BI & IPDI & DBTDL & 88 & 0.24 & W \\
\hline PU3AI & TDI & - & 88 & 0.28 & W \\
\hline PU3BI & TDI & DBTDL & 87 & 0.25 & Off-W \\
\hline
\end{tabular}


Tab. 2. Reaction Conditions for the Polymerization of PHU with Diisocyanates Using DMAc as a Solvent.

\begin{tabular}{lccccc}
\hline Polymer iisocyanate & Cat. & $\begin{array}{c}\text { Yield } \\
(\%)\end{array}$ & $\begin{array}{c}\text { Inherent } \\
\text { viscosity } \\
(\mathrm{dL} / \mathrm{g})^{\mathrm{a}}\end{array}$ & Color \\
\hline PU1All & HMDI & - & 78 & 0.18 & Off-W \\
PU1BII & HMDI & DBTDL & 69 & 0.17 & W $^{\mathrm{b}}$ \\
PU2AIl & IPDI & - & 81 & 0.19 & W \\
PU2BII & IPDI & DBTDL & 76 & 0.16 & W \\
PU3All & TDI & - & 83 & 0.20 & W \\
PU3BIl & TDI & DBTDL & 80 & 0.19 & Off-W \\
\hline${ }^{a}$ Measured at a concentration of 0.5 g/dL in DMF at $25^{\circ} \mathrm{C} .{ }^{b} \mathrm{~W}=$ White
\end{tabular}

To compare the efficiency of this novel method of polymerization (method I) with conventional method (method II) [34], which was used for the preparation of polyureas using the same monomer, higher yields and viscosities were obtained by method I. Polymerization in molten TBAB is more controllable than in $\mathrm{N}, \mathrm{N}$ dimethylacetamide (DMAc), which was used as a solvent in method II. Because, DMAc is volatile, the concentration of reaction mixture during polymerization process may be changed. Furthermore, saving time and energy is the other advantage of using TBAB in method I. This methodology offers significant advantages with regard to simplicity of operation, yield of products, reaction times, and non-toxicity of the reaction medium used. Thus, it provides a better and greener alternative for the synthesis of polymers. In addition further amounts of TBAB do not make any significant differences in polymerization processes. The obtained polyureas were characterized by FT-IR, and thermogravimetric analysis.

\section{Solubility of polyureas}

The polymers PU1, PU2 and PU3 are soluble in organic solvents such as DMF, $\mathrm{N}$ methylpyrrolidone (NMP), dimethylsulfoxide (DMSO), DMAc, and in $\mathrm{H}_{2} \mathrm{SO}_{4}$, but insoluble in solvents such as water, methanol, acetone, cyclohexane and chloroform.

\section{Thermal properties}

The thermal behavior of polyureas PU1AI, PU2AI and PU3BI were measured by thermogravimetric analysis (TGA) and derivative of thermogravimetric (DTG) analysis at a rate of $10^{\circ} \mathrm{C} / \mathrm{min}$ in a nitrogen atmosphere. An examination of the data reveals that all polyureas are thermally stable up to $220^{\circ} \mathrm{C}$. The temperatures of $5 \%$ and $10 \%$ weight loss together with char yield at $600^{\circ} \mathrm{C}$ for PU1AI, PU2AI and PU3BI are $260^{\circ} \mathrm{C}, 265^{\circ} \mathrm{C}$ and $14.0 \%, 255^{\circ} \mathrm{C}, 275^{\circ} \mathrm{C}$ and $8 \%$ and $220^{\circ} \mathrm{C}, 255^{\circ} \mathrm{C}$ and $22.0 \%$ respectively (Table 3). 


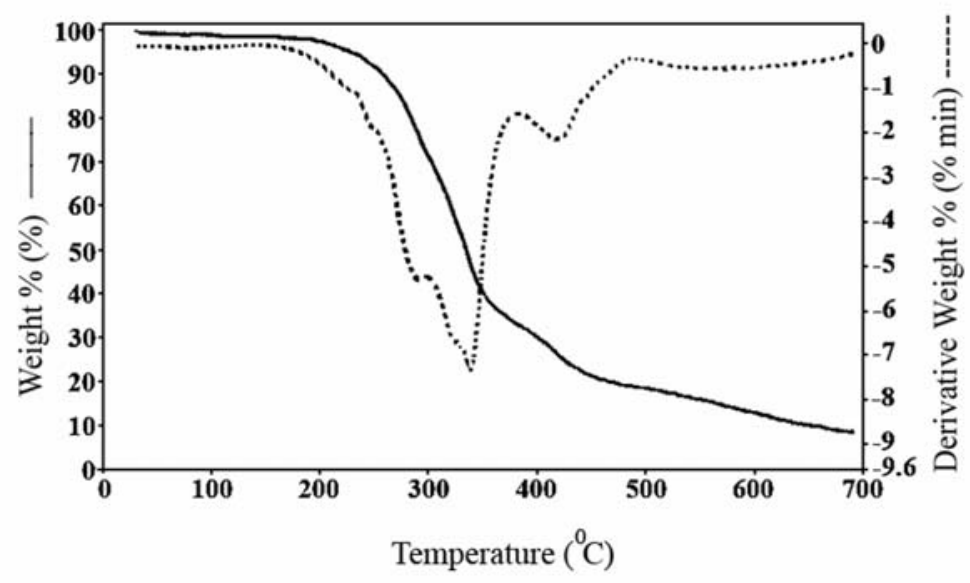

Fig. 1. TGA /DTG thermogram of PU1AI in a nitrogen atmosphere and heating rate of $10{ }^{\circ} \mathrm{C} / \mathrm{min}$.

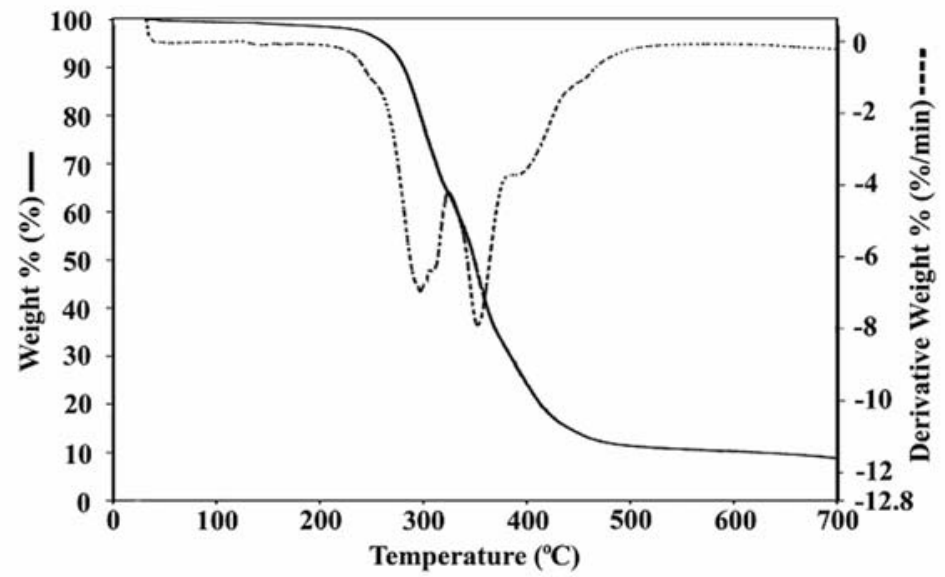

Fig. 2. TGA /DTG thermogram of PU2AI in a nitrogen atmosphere and heating rate of $10^{\circ} \mathrm{C} / \mathrm{min}$.

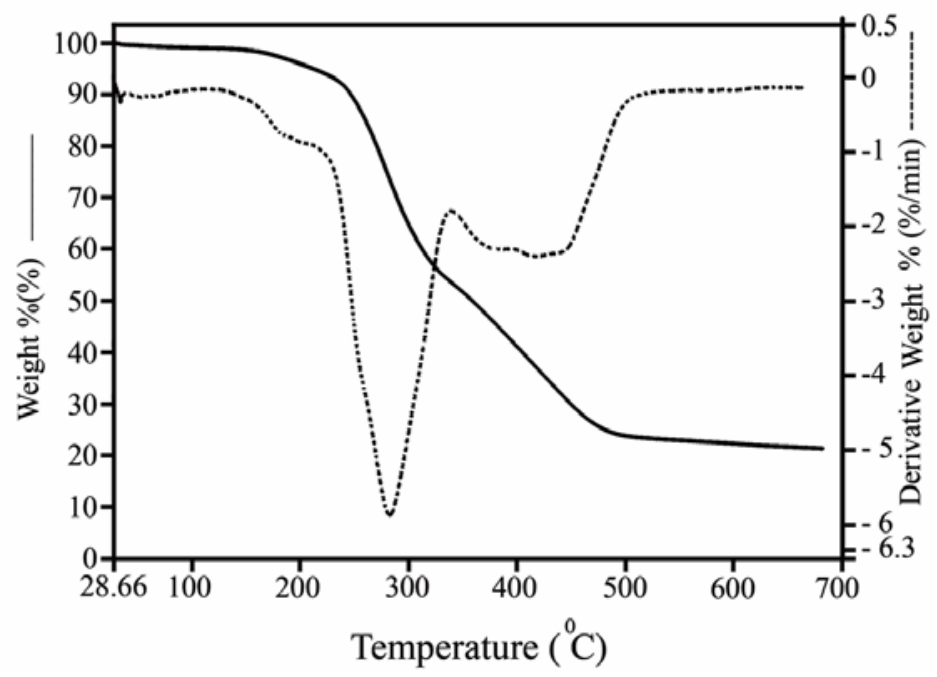

Fig. 3. TGA /DTG thermogram of PU3BI in a nitrogen atmosphere and heating rate of $10{ }^{\circ} \mathrm{C} / \mathrm{min}$. 
Figures 1, 2 and 3 show thermograms of PU1AI, PU2AI and PU3BI, respectively. The thermal behavior of these polyureas were also compared with polyureas synthesized by conventional method so, the polymers, PU1BII and PU2BII show 5\% weight loss at 240 and $200^{\circ} \mathrm{C}$, respectively.

Tab. 3. Thermal Properties of PU1AI, PU2AI and PU3BI.

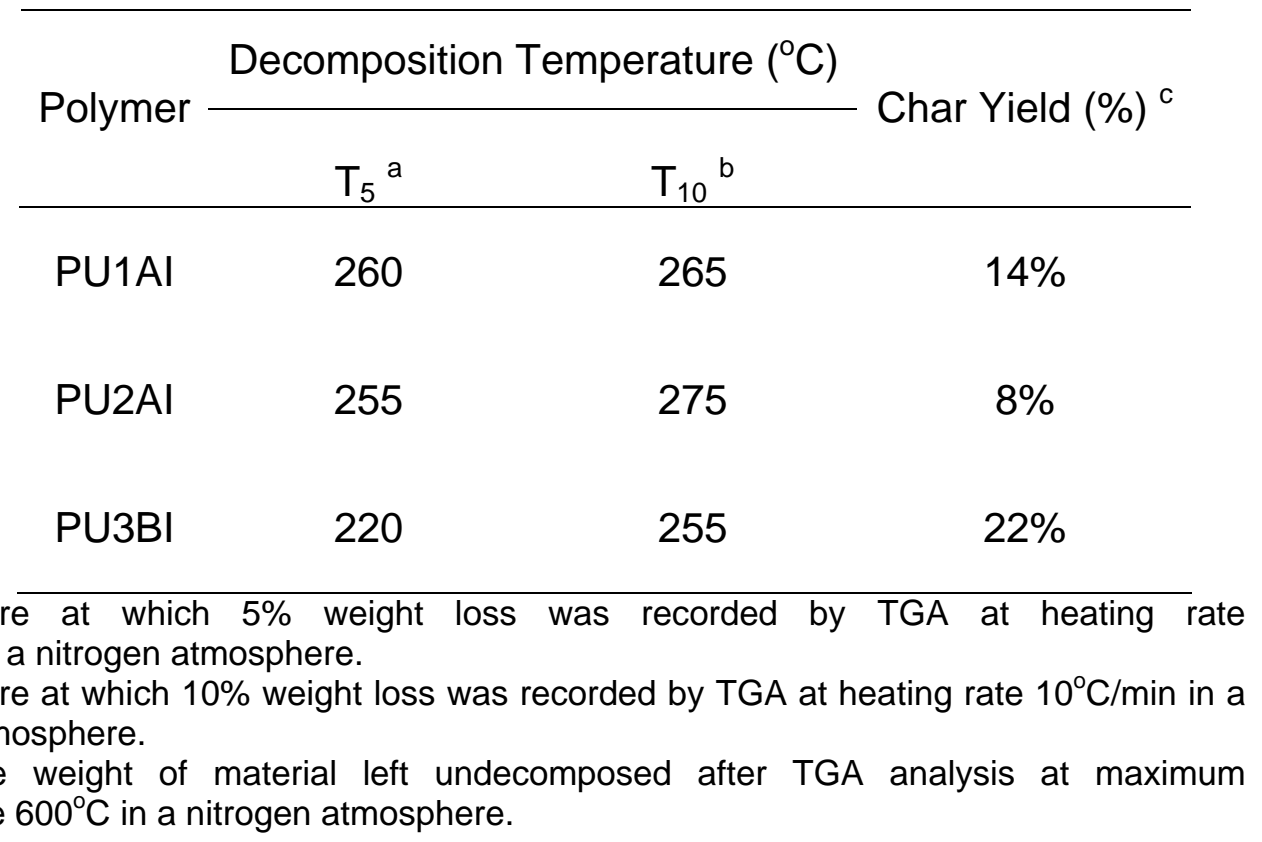

\section{Conclusions}

From this investigation it is clear that molten TBAB may act as a simple, cheap and safe medium for polymerization reactions. The reported procedure of the polymerization reaction of PHU with various diisocyanates under green conditions in the presence of TBAB as a solvent and catalyst demonstrates the potential of molten TBAB, a benign readily available IL as an efficient and recyclable catalyst [15] and holds much promise for further applications. This methodology offers significant improvements with regard to yield of products, inherent viscosities, thermal stability, simplicity in operation, cost efficiency and green aspects avoiding toxic catalysts and solvents. The resulting polymers are soluble in most organic solvents, and can be used as thermoplastic materials. In our effort we substituted DMAc (harmful solvent) with TBAB. Since DBTDL did not have any catalytic effect on this polycondensation reaction, may be the molten TBAB could have acted both as a solvent and catalyst. Moreover, the use of any organic solvent was not needed throughout the whole process of polymerization; in fact, organic solvent removal is of importance to minimize economic cost and environmental impact of chemical processes.

\section{Experimental}

\section{Materials and Equipments}

Reagents were purchased from Fluka Chemical (Buchs, Switzerland), Aldrich Chemical (Milwaukee, WI) and Riedel-deHaen AG (Seelze, Germany). PHU was synthesized according to published procedure [35]. FT-IR spectra were recorded on a Nicolet Impact $400_{D}$ IR spectrophotometer. Spectra of solids were carried out using 
$\mathrm{KBr}$ pellets. Vibrational transition frequencies are reported in wave number $\left(\mathrm{cm}^{-1}\right)$. Band intensities are assigned as weak (w), medium (m), shoulder (sh), strong (s) and broad (br). All melting points were taken with a Gallenham melting point apparatus. Inherent viscosities were measured by standard procedure using a Cannon Fenske Routine viscometer. Thermal Gravimetric Analysis (TGA) data for polymers were taken on a Stanton-650 TGA under $\mathrm{N}_{2}$ atmosphere by the Research Institute of Polymer and Petrochemical of Iran (IPPI).

\section{Polymerization of PHU with diisocyanates in molten TBAB}

A typical preparation of PU1A was as follows:

A mixture of PHU $\left(0.1091 \mathrm{~g}, 6.15 \times 10^{-4} \mathrm{~mol}\right)$ and TBAB $\left(0.1980 \mathrm{~g}, 6.13 \times 10^{-4} \mathrm{~mol}\right)$ was ground until a powder was formed. Then it was transferred into a $25-\mathrm{mL}$ roundbottom flask and HMDI (1) $\left(0.1035 \mathrm{~g}, 6.15 \times 10^{-4} \mathrm{~mol}\right)$ was added to the mixture and heated until homogeneous solution was formed. Then the solution was stirred for 12 $\mathrm{h}$ at $125{ }^{\circ} \mathrm{C}$, and the viscous solution was precipitated in $30 \mathrm{~mL}$ of $50 / 50$ methanol/water solution. The white solid was filtered off, dried to give $0.195 \mathrm{~g}(92 \%)$ of polyurea PU1AI. The above polymerization was repeated, in the presence of DBTDL as a catalyst. The other polyureas were prepared with a similar procedure.

PU1AI: m.p. 116-120ㄷ; FT-IR (KBr, cm $\left.{ }^{-1}\right)$ : $3411(\mathrm{~m}), 2954(\mathrm{~m}), 1740$ (s), $1536(\mathrm{~m})$, $1501(\mathrm{~m}), 1458(\mathrm{w}), 1415$ (s), $1310(\mathrm{w}), 1246(\mathrm{~m}), 1066(\mathrm{~m}), 1024(\mathrm{w}), 764(\mathrm{~m}), 618$ (w), $1504(w), 417(w)$.

PU2BI: m.p. $137^{\circ} \mathrm{C}$; FT-IR (KBr, cm $\left.{ }^{-1}\right)$ : $3339(\mathrm{~m}), 3069(\mathrm{w}), 2956(\mathrm{~m}), 2928(\mathrm{~m}), 1735$ (s), 1638 (w), 1540 (s), 1501 (m), 1457 (w), 1417 (s), 1365 (m), $1244(\mathrm{~m}), 1148(\mathrm{w})$, $1050(\mathrm{w}), 1024(\mathrm{w}), 766(\mathrm{~m}), 690(\mathrm{w}), 618(\mathrm{w}), 504(\mathrm{w})$.

PU3AI: m.p. $138^{\circ} \mathrm{C}$; FT-IR (KBr, $\left.\mathrm{cm}^{-1}\right)$ : $3365(\mathrm{~m}), 3100(\mathrm{w}), 2953(\mathrm{~m}), 1742$ (s), 1637 (w), $1534(\mathrm{~m}), 1501(\mathrm{~m}), 1458(\mathrm{w}), 1414(\mathrm{~s}), 1309(\mathrm{w}), 1212(\mathrm{~m}), 1063(\mathrm{w}), 1024(\mathrm{w})$, $765(w), 690(w)$.

\section{Acknowledgements}

We wish to express our gratitude to the Research Affairs Division, Isfahan University of Technology (IUT), Isfahan, for partial financial support. Further financial support from the Center of Excellency in Chemistry Research (IUT) is gratefully acknowledged. We would also like to thank Mrs. Zadhoush for the reading proof of this manuscript and Mr. M. Kolahdoozan, Miss Z. Rafiee and Miss S. Meratian for their helpful discussion.

\section{References}

[1] Ranu, B. C.; Banerjee, S. Org. Lett. 2005, 14, 3049.

[2] Wasserscheid, P.; Keim. W. Angew. Chem. Int. Ed. 2000, 39, 3773.

[3] Marsh, K. N. Fluid Phase Equilib. 2004, 219, 93.

[4] Welton, T. Chem. Rev. 1999, 99, 2071.

[5] Weng, J.; Weng, C.; Li, H.; Weng, Y. Green Chem. 2006, 8, 96.

[6] Blanchard, L. A.; Hancu, D. E.; Beckman, J.; Brennecke, J. F. Nature 1999, 399, 28.

[7] David, M.; Eike, J.; Brennecke, F.; Edward, J. M. Green Chem. 2003, 5, 323.

[8] Sun. J.; Fujita. S.; Bhalchandra, M.; Bhanage, M. Catal. Commun. 2004, 5, 83.

[9] Jain, N.; Kumar, A.; Chauhan, S.; Chauhan, S. M. S. Tetrahedron 2005, 61, 1015. [10] Mallakpour, S.; Kowsari, E.; J. Polym. Sci. Part A: Polym. Chem. 2005, 43, 6545. 
[11] Mallakpour, S.; Kowsari, E. Iranian Polym. J. 2006, 15 (3), 239.

[12] Vygodskii, Y. S.; Lozinskaya, E. I.; Shaplov, A. S.; Konstantin, A.; Lyssenko, K. A.; Antipin, M. Y.; Urman, Y. G. Polymer 2004, 45, 5031.

[13] Lozinskaya, E. I.; Shaplov, A. S.; Vygodskii. Ya. S. Eur. Polym. J. 2004, 40, 2065.

[14] Khodaei, M. M.; Khosropour, A. R.; Ghozat. K. Tetrahedron Lett. 2004, 45, 3525.

[15] (a) Ranu, B. C.; Dey, S. S. Tetrahedron Lett. 2003, 44, 865. (b) Ranu, B. C.;

Dey, S. S.; Hajra, A. Tetrahedron 2003, 2417.

[16] Mallakpour, S.; Rafiee, Z. Eur. Polym. J. 2007, in press.

[17] Brindaban, C.; Ranu, A. D.; Sampak, S. J. Chem. Soc. Perkin Trans. 2002, 1, 1520.

[18] Zhao, D. B.; Wu. M.; Kou, Y.; Min, E. Z. Catal. Today 2002, 74, 157.

[19] Holbrey. J. D.; Seddon, K. R. Clean Prod. Proc. 1999, 1, 223.

[20] Kubisa, P. Prog. Polym. Sci. 2004, 29, 3.

[21] Mallakpour, S.; Rafiee, Z. J. Appl. Polym. Sci. 2004, 91, 2103.

[22] Mallakpour, S.; Rafiee, Z. Iranian Polym. J. 2005, 14 (12), 1066.

[23] Jikihara T, Matsuya K, Ohta H, Suzuki S, Wakabayashi O. (1981) US, 4, 249, 934, Japan.Chemical Abstract 95, 62219y.

[24] Simlot R, Izydore RA, Wong OT, Hall AH. (1994) J. Pharm. Sci. 83: 367.

[25] Paquette LA, Kretschmer G. (1979) J. Am. Chem. Soc. 101: 4655.

[26] Ulrich, H.; in Encyclopedia of Chemical Technology Wiley-Interscience, New York, Ch. 1983, 23, 576.

[27] Morgan, P. W.; Condensation Polymers by Interfacial and Solution Methods, Wiley-Interscience, New York, 1965, Chap. 5.

[28] Mallakpour, S.; Rafiee, Z. J. Appl. Polym. Sci. 2004, 91, 2103.

[29] Mallakpour. S.; Rezazadeh, S. Iranian Polym. J. 2004, 13 (1), 29.

[30] Chantarasiri, N.; Choprayoon, C.; Thussanee, M. P.; Nongnuj, M. N.; Polym. Degrad. \& Stab. 2004. 86, 505.

[31] Steuben, K. C.; Barnabeo, A. E.; Interfacial Synthesis, Millich, F.; Carraher, C.E.; Ed.; Vol. 2, Dekker, New York 1977, Chap.18.

[32] Mallakpour, S. E.; Sheikholeslami, B. Iranian Polym. J. 1999, 8 (1), 61.

[33] Pal, S. K.; Kumar, S. Tetrahedron Lett. 2006, 47, 8993.

[34] Mallakpour, S. E. J. Chem. Educ. 1992, 69, 238 